\title{
Negative pressure ventilation versus conventional mechanical ventilation in the treatment of acute respiratory failure in COPD patients
}

\author{
A. Corrado*, M. Gorini*, R.Ginanni*, C. Pelagatti+, G. Villella*, U. Buoncristiano , F. Guidi”, \\ E. Pagni**, A. Peris**, E. De Paola*
}

Negative pressure ventilation versus conventional mechanical ventilation in the treatment of acute respiratory failure in COPD patients. A. Corrado, M. Gorini, R. Ginanni, C.Pelagatti, G. Villella, U. Buoncristiano, F. Guidi, E. Pagni. A. Peris, E. De Paola. CERS Journals Ltd 1998.

ABSTRACT: This case-control study was aimed to evaluate the effectiveness of negative pressure ventilation (NPV) versus conventional mechanical ventilation (CMV) for the treatment of acute respiratory failure (ARF) in patients with chronic obstructive pulmonary disease (COPD) admitted to a respiratory intermediate intensive care unit (RIICU) and four general intensive care units (ICU).

Twenty-six COPD patients in ARF admitted in 1994-95 to RIICU and treated with NPV (cases) were matched according to age ( $\pm 5 \mathrm{yrs})$, sex, causes triggering ARF, Acute Physiology and Chronic Health Evaluation (APACHE) II score ( \pm 5 points), pH $( \pm 0.05)$ and arterial carbon dioxide tension $\left(\mathrm{Pa}_{2}, \mathrm{CO}_{2}\right)$ on admission with 26 patients admitted to ICU and treated with CMV (controls). The primary end points of the study were inhospital death for both groups and the need for endotracheal intubation for cases. The secondary endpoints were length and complications of mechanical ventilation and length of hospital stay.

The effectiveness of matching was $91 \%$. Mortality rate was $23 \%$ for cases and $27 \%$ for controls (ns), five cases needed endotracheal intubation, four of whom subsequently died. The duration of ventilation in survivors was significantly lower in cases than in controls, with a median of $16 \mathrm{~h}$ (range 2-111) versus $96 \mathrm{~h}$ (range 12-336) $(P<0.02)$, whereas the length of hospital stay was similar in the two groups, with a median of 12 days (range 2-47) for cases $v s 12$ days (range 3-43) (Ns) for controls. No complications were observed in cases, whereas three controls developed infective complications.

These results suggest that negative pressure ventilation is as efficacious as conventional mechanical ventilation for the treatment of acute respiratory failure in patients with chronic obstructive pulmonary disease and that it is associated with a shorter duration of ventilation and a similar length of hospital stay compared with conventional mechanical ventilation.

Eur Respir J 1998; 12: 519-525.
*Unita' di Terapia Intensiva Polmonare e Fisiopatologia Toracica, Dipartimento di Pneumologia, Villa di Ognissanti and **U.O. di Rianimazione, Ospedale di Careggi, Firenze, Italy. ${ }^{+}$U.O. di Rianimazione Ospedale di S. Maria Nuova, Firenze, Italy. ҰU.O. di Rianimazione Ospedale S Maria Annunziata, Firenze, Italy. \#U.O. di Rianimazione, Ospedale SS Cosma e Damiano, Pescia, Italy.

Correspondence: A. Corrado

Unita' di Terapia Intensiva Polmonare e Fisiopatologia

Toracica

Dipartimento di Pneumologia

Villa di Ognissanti

Azienda Ospedaliera di Careggi

Viale Pieraccini 24

I-5 0136 Florence

Italy

Fax: 39554277330

Keywords: Acute respiratory failure chronic obstructive pulmonary disease conventional mechanical ventilation general intensive care unit negative pressure ventilation respiratory intermediate intensive care unit

Received: June 191997

Accepted after revision March 131998
Patients with chronic pulmonary disease frequently need mechanical ventilatory support for acute exacerbation of the disease. In these patients, however, endotracheal intubation and mechanical ventilation lead to several complications including tracheal injury, barotrauma, nosocomial pneumonia, and weaning difficulty [1]. Complications and difficulty in weaning are the major factors in increasing the duration of hospitalization and for high costs, principally linked to the length of stay in very expensive facilities such as intensive care units (ICU).

It has been shown that, in chronic obstructive pulmonary disease (COPD) patients with acute respiratory failure (ARF), noninvasive positive pressure ventilation (NIPPV) reduces the need for endotracheal intubation [2-4], the length of hospital stay [2,3] and the inhospital mortality rate [2-5], compared with standard therapy. The imple-

For editorial comment see page 515 mentation of NIPPV at a much earlier stage in the course of respiratory failure than that at which intubation is normally considered could prevent the development of a severe acidosis, which has been found to be a poor prognostic feature for recovery [6]. The selection of patients is a crucial factor in the success of NIPPV [7] and this means that patients more severely ill than those included in previous studies [2-5] could not benefit from noninvasive mechanical ventilation; in these cases, conventional mechanical ventilation after intubation must be provided promptly. A recent study, however, has reported that COPD patients with severe respiratory acidosis and hypercapnic coma were successfully treated with a noninvasive ventilatory technique using negative pressure ventilation [8]. Direct comparisons between noninvasive and conventional mechanical ventilation in the treatment of COPD patients with ARF are scarce. In the only retrospective study, published recently by VITACCA et al. [9], the control 
group was historical. The present study compared COPD patients with ARF admitted to two different settings: a respiratory intermediate intensive care unit (RIICU) where negative pressure ventilation (NPV) was used as the first line of treatment and a general ICU where conventional mechanical ventilation (CMV) was used as the first line of treatment. The aim of this matched study was to investigate whether there were differences in the outcome and complications which could be related to the different ventilatory treatments employed.

\section{Patients and methods}

\section{Study design and patient selection}

This matched, retrospective, cohort study was performed in patients with COPD in ARF who were admitted to the RIICU of Careggi Hospital, Florence, and to the ICU of Careggi Hospital, Florence, Annunziata Hospital, Florence, Santa Maria Nuova Hospital, Florence, and San Cosma e Damiano Hospital, Pescia, from January 11994 to December 31 1995. The patients admitted to the RIICU and submitted to NPV were designated as "cases" and those admitted to ICU and submitted to CMV as "controls". The level of assistance (nurse/patient ratio) was different in the two settings: $1 / 3$ for the RIICU and $1 / 1$ for the ICU.

\section{Definitions}

Cases. Patients admitted to the RIICU with the inclusion criteria of COPD and ARF and the need for endotracheal intubation were designated as cases. The diagnosis of COPD was established when, in a clinical stable condition, the forced expiratory volume in one second (FEV1) was $70 \%$ predicted and FEV1/vital capacity (VC) was lower than $70 \%$ after bronchodilators. In the absence of lung function measurements, COPD was defined by the following criteria: a history of productive chronic cough and dyspnoea dating over 10 yrs in heavy smokers and radiological evidence of hyperinflation.

ARF was defined as a condition of acute exacerbation of the chronic disease characterized by at least three of the following criteria: acute worsening of dyspnoea, signs of right heart failure (ankle oedema), severe hypoxaemia (arterial oxygen tension $\left(\mathrm{Pa}, \mathrm{O}_{2}\right)$ /inspiratory oxygen fraction $\left(F \mathrm{I}, \mathrm{O}_{2}\right)<31.9$ ), hypercapnia (arterial carbon dioxide tension $\left.\left(\mathrm{Pa}_{\mathrm{a}} \mathrm{CO}_{2}\right)>9.3 \mathrm{kPa}\right)$ and blood $\mathrm{pH}<7.30$.

The need for endotracheal intubation and mechanical ventilation was established on the basis of clinical and blood gases worsening despite intensive pharmacological treatment and optimal oxygen administration or when a comatose state was present.

Exclusion criteria were: postoperative conditions, restrictive disorders (kyphoscoliosis, neuromuscular disorders, fibrothorax) as the cause of chronic respiratory failure, neurological disorders unrelated to hypercapnia or hypoxaemia, acute myocardial infarction, left heart failure, adult respiratory distress syndrome, acute and chronic renal failure, neoplasia and pulmonary embolism.
Controls. A control was defined as a patient similar to a case but admitted to an ICU. The variables used for matching individual cases were the following: age ( $\pm 5 \mathrm{yrs})$, sex, causes triggering ARF, Acute Physiology and Chronic Health Evaluation (APACHE) II [10] score calculated within the first $24 \mathrm{~h}$ of admission ( \pm 5 points), blood $\mathrm{pH}$ on admission $( \pm 0.05), \mathrm{Pa}_{\mathrm{a}} \mathrm{CO}_{2}$ on admission $( \pm 0.8 \mathrm{kPa}$ of the value for the case when that value was $<9.3 \mathrm{kPa}$ and within $1.6 \mathrm{kPa}$ when the value was $\breve{S} 9.3 \mathrm{kPa}$ ). When more than one potential control was well matched to a case, the control with the nearest data was selected.

The comparability of the two groups was evaluated on the basis of the following data on admission: the $\mathrm{Pa}, \mathrm{O}_{2} /$ $F \mathrm{I}, \mathrm{O}_{2}$ ratio, the plasma bicarbonate levels and the Glasgow coma score [11]. Moreover, values of arterial blood gases at the time of discharge in survivors were analysed as further criteria of comparability.

Pulmonary functional data performed in a stable condition 1-12 months before ARF were considered for further evaluations.

\section{Modalities of treatment and outcome assessment.}

All patients received oxygen therapy in order to obtain a $\mathrm{Pa}, \mathrm{O}_{2}$ between $8-9.3 \mathrm{kPa}$, as well as standard drugs (inhaled $\beta_{2}$ agonists, cardiokinetic agents, i.v. aminophylline, i.v. diuretics, i.v. steroids and i.v. antibiotics). When medical treatment failed the patients admitted to RIICU (cases) were treated with NPV as a first line therapy provided by the iron lung (Mod. CZ800 and Mod.C 900; Coppa Co., Biella, Italy), whereas the patients admitted to the ICU (controls) were treated with traditional mechanical ventilation, after endotracheal intubation. In these patients the following ventilatory modalities were applied: controlled mechanical ventilation (eight patients), pressure-controlled ventilation (12 patients) and assisted control ventilation (six patients), followed by pressure support ventilation.

Iron lung settings for cases were similar to those reported previously [8]. The ventilatory treatment was carried out continuously until the recovery of a good level of spontaneous breathing. Then, ventilatory treatment was provided intermittently until stable levels of blood $\mathrm{pH}$ (7.37-7.40) were reached. The ventilator was set at a rate ranging from 11-27 breaths $\mathrm{min}^{-1}$ on the basis of the respiratory frequency of patients; the negative pressures were chosen to elicit a tidal volume $(V \mathrm{~T})$ at least $6 \mathrm{~mL} \cdot \mathrm{kg}^{-1}$ (recorded at the mouth by means of a Wright's ventilograph).

The ventilatory treatment with the iron lung was judged to be inadequate when there was evidence of an insufficient control of the upper airways or when one of the following conditions occurred: a) satisfactory ventilation $(V \mathrm{~T}$ $>5 \mathrm{~mL} \cdot \mathrm{kg}^{-1}$ ) and a substantial improvement in gas exchange $\left(P \mathrm{a}, \mathrm{CO}_{2}\right.$ decrease of $<1.3 \mathrm{kPa}$ and $P \mathrm{a}, \mathrm{O}_{2}>8 \mathrm{kPa}$ within 1 hour of the start of mechanical ventilation) could not be obtained despite optimal setting of the ventilator, or b) worsening of the comatose state despite an improvement in gas exchange (within 12-24 h of the start of mechanical ventilation). Under these circumstances, endotracheal intubation was performed and mechanical ventilation was provided by means of the iron lung. The setting of the iron lung was properly modified in order to obtain a $V$ T at least 
$6 \mathrm{~mL} \cdot \mathrm{kg}^{-1}$ and oxygen was provided through a lateral port of a piece tube added to the endotracheal tube. When the iron lung failed to maintain adequate oxygenation, intermittent positive pressure ventilation was given. Endotracheal intubation was not performed when patients (or relatives when the patient was unconscious) refused this procedure.

\section{Definition of the study endpoints}

To assess the efficacy of both ventilatory techniques in each individual patient, primary endpoints were defined as death during ICU stay in patients treated with conventional mechanical ventilation and with the iron lung or the need for intubation due to inefficacy of the iron lung. Treatment failure was defined as death for controls and as death or the need for endotracheal intubation for cases.

Secondary endpoints were complications (pneumonia, pneumothorax) linked to mechanical ventilation, duration of ventilatory assistance and length of ICU stay.

\section{Statistical evaluation}

Continuous variables were compared using the Student's t-test for normally distributed variables and the Wilcoxon rank sum test for non-normally distributed variables. The McNemar test with continuity correction was used to compare the mortality and the treatment rates between the two groups [12]. The odds ratio of mortality and treatment failure rate with the relative $95 \%$ confidence interval (CI) was determined using the Mantel and Haenszel method [12]. A p-value $<0.05$ was considered as statistically significant. Unless otherwise indicated, all data are presented as mean \pm SD.

\section{Results}

\section{Patients included in the study}

Out of a total of 283 patients with COPD in ARF, admitted to the RIICU in Florence and the three ICUs in Florence and the ICU in Pescia from January 11994 to December 31 1995, 26 pairs met the inclusion criteria and were therefore evaluated. The patients reported herein included no cases of readmission. The patients' location prior to admission to the RIICU and ICU was: emergency room in 11 and 13 patients, respectively, and medical division in 15 and 11 patients, respectively.

\section{Effectiveness of matching}

In the matched groups, $100 \%$ were age matched to within 5 yrs; $100 \%$ were sex matched, $69 \%$ had the same causes triggering ARF, $100 \%$ had an APACHE II score within $5,100 \%$ had a blood $\mathrm{pH}$ on admission within 0.05 and $77 \%$ had a $\mathrm{Pa}, \mathrm{CO}_{2}$ within the defined criteria (table 1).
Table 1. - Results of matching of cases to controls using six criteria

\begin{tabular}{lcc}
\hline \multirow{2}{*}{ Criterion } & \multicolumn{2}{c}{$\begin{array}{c}\text { Proportion of cases } \\
\text { matched to controls }\end{array}$} \\
\cline { 2 - 3 } & $\mathrm{n} / \mathrm{n}$ & $\%$ \\
\hline Age \pm 5 yrs & $26 / 26$ & 100 \\
$\mathrm{Sex}$ & $26 / 26$ & 100 \\
Causes triggering ARF & $18 / 26$ & 69 \\
Apache II score \pm 5 & $26 / 26$ & 100 \\
pH on admission \pm 0.05 & $26 / 26$ & 100 \\
$P \mathrm{a}, \mathrm{CO}_{2}$ on admission & $20 / 26$ & 77 \\
$\quad \pm 6$ when the value was $<70 \mathrm{mmHg}$ & & \\
and \pm 12 when the value was $\breve{\mathrm{S}} 70$ & & \\
mmHg & & \\
\hline
\end{tabular}

ARF: acute respiratory failure; $P \mathrm{a}_{\mathrm{a}} \mathrm{CO}_{2}$ : arterial carbon dioxide tension. APACHE: Acute Physiology and Chronic Health Evaluation. $(1 \mathrm{mmHg}=0.133 \mathrm{kPa}$. $)$

The overall effectiveness of matching for the variables used reached $91 \%$.

Concerning the variables used for matching (table 2) the median age was 72 yrs (range 54-82) for the cases and 70.5 yrs (range 50-85) for the controls. The median APACHE II score was 26 (range 17-33) and 24.5 (range 14-38) for the cases and controls, respectively. The most frequent cause triggering $\mathrm{ARF}$ was exacerbation (77\% and $84.6 \%$ for the cases and controls, respectively), whereas pneumonia caused ARF in $19 \%$ of cases and $15 \%$ of controls. In one patient in the cases group, sedation was responsible for ARF. The median blood $\mathrm{pH}$ on admission was 7.25 (range 7.02-7.33) for the cases and 7.23 (range 7.03-7.35) for the controls. Among the cases, the median $P \mathrm{a}, \mathrm{CO}_{2}$ on admission was $12.8 \mathrm{kPa}$ (range 10 16) compared with $11.9 \mathrm{kPa}$ (range 8.5-16.1) among the controls. The sex ratio was the same in the two groups. The comparability of the two groups was also assessed by comparing six other criteria that evaluated the severity of ARF on admission and the level of chronic respiratory failure at discharge (table 3 ). There was no significant difference in these variables between the cases and controls.

The respiratory functional data of both groups of patients are reported in table 4 . These data were available in $33 \%$ of all patients (10 cases and seven controls). The degree of hyperinflation was similar in the two groups, whereas bronchial obstruction tended to be lower in the cases (FEV1 $31.1 \pm 9.5 \%$ pred) than in the controls (FEV 1 $42.7 \pm 16.1 \%$ pred). This difference, however, was not statistically significant.

Table 2. - Clinical factors used for matching

\begin{tabular}{lcc}
\hline & Cases & Controls \\
\hline Sex, M/F & $15 / 11$ & $15 / 11$ \\
Age, yrs* & $70.9 \pm 7.2$ & $69.9 \pm 8.9$ \\
Causes triggering ARF ${ }^{\dagger}$ & & \\
$\quad$ Exacerbations & 20 & 22 \\
$\quad$ Pneumonia & 5 & 4 \\
$\quad$ Sedative agents & 1 & 0 \\
APACHE II score* & $24.9 \pm 4.7$ & $24.5 \pm 4.9$ \\
pH on admission* & $7.24 \pm 0.07$ & $7.23 \pm 0.08$ \\
$P$ a, $\mathrm{CO}_{2}$ on admission $\mathrm{kPa}^{*}$ & $12.7 \pm 1.5$ & $11.9 \pm 1.7$ \\
\hline $\mathrm{M}:$ male; F* female; ARF: acute respiratory failure; $\mathrm{Pa}_{\mathrm{a}} \mathrm{CO}_{2}$
\end{tabular}

: acute respiratory failure; arterial carbon dioxide tension. APACHE: Acute Physiology and Chronic Health Evaluation. *mean \pm sD; ${ }^{\dagger}$ : number. 
Table 3. - Comparison of unmatched criteria

\begin{tabular}{lcc}
\hline & Cases & Controls \\
\hline $\mathrm{P}_{\mathrm{a}, \mathrm{O}_{2}} / F \mathrm{I}, \mathrm{O}_{2}$ on admission $\mathrm{kPa}$ & $24.0 \pm 6.3$ & $23.1 \pm 5.8$ \\
$\mathrm{HCO}_{3}$ on admission mmol $\cdot \mathrm{L}^{-1}$ & $40.3 \pm 4.3$ & $38.7 \pm 4.2$ \\
$\mathrm{Glasgow}$ Coma Score on admission & $10.9 \pm 3.6$ & $11.6 \pm 3.6$ \\
${\mathrm{~Pa}, \mathrm{O}_{2} / \mathrm{F}, \mathrm{O}_{2} \text { at discharge* } \mathrm{kPa}}_{P \mathrm{a}, \mathrm{CO}_{2} \text { at discharge* } \mathrm{kPa}}^{39.3 \pm 3.8}$ & $38.6 \pm 5.9$ \\
$\mathrm{pH}$ at discharge* & $7.6 \pm 1.6$ & $7.9 \pm 1.8$ \\
\hline
\end{tabular}

Value are expressed as mean \pm SD. *: these values refer to survivors. $\mathrm{Pa}, \mathrm{O}_{2}$ : arterial oxygen tension; $\mathrm{F}_{\mathrm{I}} \mathrm{O}_{2}$ : inspiratory oxygen fraction; $\mathrm{Pa}_{\mathrm{a}} \mathrm{CO}_{2}$ : arterial carbon dioxide tension. There were no statistically significant differences between the groups.

\section{Primary endpoints}

Mortality. The mortality rate in cases was $23.1 \%$, compared with $27 \%$ for the controls (table 5). Seventeen pairs had a concordant outcome (15 surviving pairs and two nonsurviving pairs), leaving nine pairs with a discordant outcome. Among the discordant pairs McNemar's test showed no significant difference $\left(\chi^{2}=0.0\right.$, ns). The estimated mortality risk ratio was 0.8 (95\% CI: 0.26-1.08).

Among the six cases who died (all during hospitalization), three were not weaned but refused endotracheal intubation and three, even though weaned, died of extrarespiratory complications such as cardiac arrest $(n=2)$ and sepsis $(n=1)$.

Among the seven controls who died, five were not weaned and two, even though weaned, died from acute myocardial infarction 36 and $150 \mathrm{~h}$, respectively after the discontinuation of ventilatory treatment.

Treatment failure. The treatment failure was $27 \%$ in cases and $27 \%$ in controls (table 5). Sixteen pairs had a concordant outcome. Among the 10 discordant pairs $\mathrm{McNe}-$ mar's test showed no statistical difference $\left(\chi^{2}=0.1\right.$, ns $)$. The estimated treatment failure risk ratio was 1 (95\% CI: 0.46-2.46). Five cases needed intubation, but three refused it; four of these five patients subsequently died.

\section{Secondary endpoints}

Complications. None of the cases developed infective complications during the ventilatory treatment or during hospitalization. Two patients reported uneasiness and back pain and two others suffered vomiting during NPV.

Table 4. - Respiratory functional data of chronic obstructive pulmonary disease patients in acute respiratory failure

\begin{tabular}{lcc}
\hline & Cases & Controls \\
\hline Number of patients & 10 & 7 \\
FEV1 \% pred & $31.1 \pm 9.5$ & $42.7 \pm 16.1$ \\
VC \% pred & $67.3 \pm 13.8$ & $75.3 \pm 26.4$ \\
FEV1/VC & $34.5 \pm 9.8$ & $39.6 \pm 6.2$ \\
RV \% pred & $145 \pm 25.0$ & $145 \pm 42$ \\
TLC \% pred & $104 \pm 9.4$ & $98 \pm 17$ \\
\hline
\end{tabular}

Values are expressed as mean \pm SD. FEV1: forced expiratory volume in one second; VC: vital capacity; RV: residual volume; TLC: total lung capacity. There were no statistically significant differences between the groups.
Table 5. - Treatment failure, deaths and complications in cases and controls

\begin{tabular}{lcccc}
\hline & $\begin{array}{c}\text { Number of } \\
\text { patients }\end{array}$ & $\begin{array}{c}\text { Treatment } \\
\text { failure }\end{array}$ & Deaths & Pneumonia \\
\hline Cases & 26 & 7 & 6 & 0 \\
Controls & 26 & $\begin{array}{c}(26.9) \\
7\end{array}$ & $\begin{array}{c}(23.1) \\
7\end{array}$ & 3 \\
& & $(26.9)$ & $(26.9)$ & \\
\hline
\end{tabular}

Data are expressed as number of subjects with percentage rate in parentheses. There were no statistically significant differences between the groups.

Three controls developed pneumonia during mechanical ventilation, which was fatal in one of them.

Duration of mechanical ventilation. Mechanical ventilation in survivors was applied for a median of 4.5 (1-17) days in the cases and a median of 4 (1-14) days in controls. The analysis performed among the 15 concordant surviving pairs showed no significant differences. The total number of hours of mechanical ventilation was lower in the cases, with a median of 16 (range 2-111) $\mathrm{h}$, than in the controls, with a median of 96 (12-336) h; the difference in the 15 concordant surviving pairs was statistically significant ( $\mathrm{p}<0.02$, fig. 1$)$.

Hospital stay. The median length of stay in the ICU for the cases who survived was 12 (range 2-47) days, while the median for the controls was 12 (range 3-43) days. Statistical analysis of the 15 matched pairs that survived did not show any significant difference (fig. 2).

\section{Discussion}

The data in this study failed to demonstrate a difference in either the mortality rate or the length of stay in the ICU between patients with COPD and ARF treated with noninvasive ventilation in RIICU and those treated with conventional mechanical ventilation in the ICU. However, the

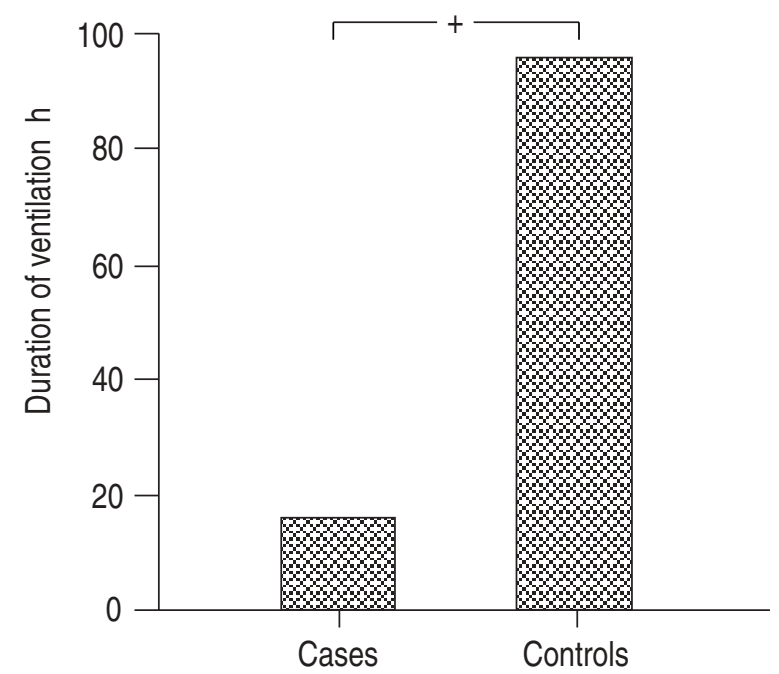

Fig. 1. - Total duration of ventilation (median) in the two groups of patients treated with negative pressure ventilation (cases) and conventional positive pressure ventilation (controls). ${ }^{+}: \mathrm{p}<0.02$, significant difference between groups. 


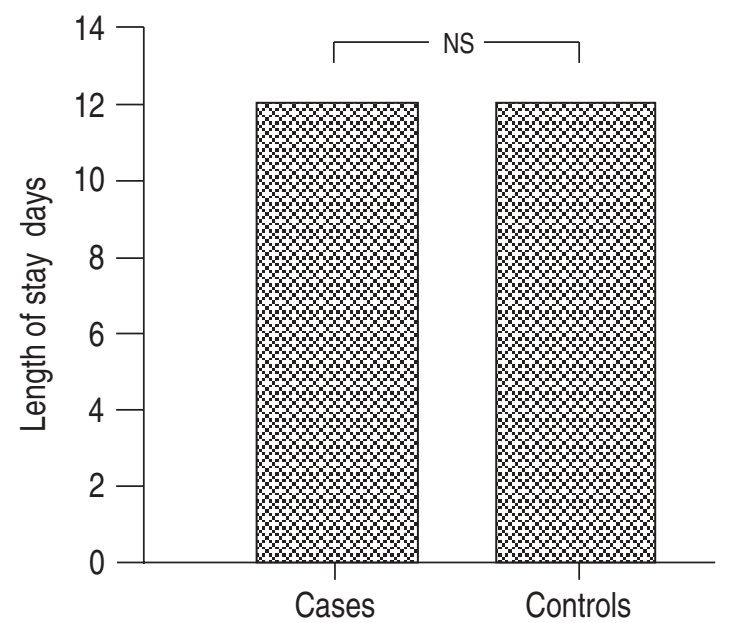

Fig. 2. - Length of hospital stay (median) in the two groups of patients treated with negative pressure ventilation (cases) and conventional positive pressure ventilation (controls).

duration of mechanical ventilation needed to regain a stable clinical condition was significantly shorter in patients treated with NPV than in those with CMV.

This retrospective study is the first to compare formally a noninvasive ventilatory technique with conventional mechanical ventilation for the treatment of COPD patients in ARF. A crucial factor for the validity of this study is the success in matching cases and controls for important confounding variables, especially the severity of ARF. Five variables significantly related the outcome in COPD patients admitted to the ICU for ARF were used for matching cases and controls: age [13, 14], cause of exacerbation [15, $16]$, blood $\mathrm{pH}$ on admission $[17,18], \mathrm{Pa}_{1} \mathrm{CO}_{2}$ on admission $[19,20]$ and APACHE II score [21]. In addition, because some studies have reported that sex affects long-term survival in COPD patients [22, 23], cases and controls were matched for sex. The overall effectiveness of matching for these variables reached $91 \%$. To verify the adequacy of the matching for severity of chronic disease and ARF, the cases and controls were compared with respect to eight other potentially confounding variables, including the plasma bicarbonate concentration on admission (a reflection of the degree of chronic hypercapnia), the $\mathrm{Pa}, \mathrm{O}_{2} / F \mathrm{I}, \mathrm{O}_{2}$ ratio on admission and Glasgow Coma Score. No significant differences were observed in these indices between cases and controls. It was thus assumed that the patients in the two groups were comparable with regard to the severity of both the chronic respiratory disease and acute decompensation. The degree of bronchial obstruction, analysed in a subgroup of patients, tended to be more severe in cases than in controls. However, because it has been reported [24] that in COPD patients a low FEV1 is a negative prognostic factor for the outcome of acute decompensation, this finding may be considered an aggravating prognostic factor for cases.

The RIICU can be considered as a reasonable alternative to the ICU for patients with less severe acute respiratory failure [25]. The data in the present study, however, suggest that even though there was a difference between the RIICU and ICU concerning the level of assistance (nursing/patient ratio: 1/3 in RIICU and 1/1 in ICU) and the modalities of ventilation, the outcome was also similar for COPD patients with severe ARF.
Intubation and mechanical ventilation of patients (especially those with COPD) may cause significant complications [1, 26, 27] which may, in turn, be associated with a poor outcome [26] and poor prognosis at 12 months [4, 9, 24]. Mortality rates following intubation and mechanical ventilation range from $22 \%$ [24] to $80 \%$ [28]. SLUITER et al. [29] reported a high mortality rate $(78 \%)$ in COPD patients with ARF who failed conservative treatment before being intubated and mechanically ventilated. It has been suggested [30], however, that this negative result could be related to the selection of patients with a poor prognosis rather than to any inherent risk of mechanical ventilation itself. This suggestion has recently been confirmed by SeNEFF et al. [13], who showed that conventional mechanical ventilation in COPD patients on admission to the ICU did not influence either short- or long-term outcome. The present data are in keeping with this suggestion. The present study failed to demonstrate a difference in the mortality rate between patients treated with conventional mechanical ventilation and those treated with noninvasive ventilation, considering that the degree of severity of acute illness and chronic functional impairment were shared equally between the two groups. Moreover, this result suggests that the use of NPV in the management of COPD patients with ARF exposes the patients to at least the same risk of death as that of conventional mechanical ventilation. It has been reported that NPPV is more successful than medical treatment alone in avoiding endotracheal intubation and its attendant complications [2-4] and in reducing the mortality rate $[2,3,5]$ and the length of hospital stay [2, 4] in selected COPD patients with ARF. The exact time at which noninvasive ventilation should be introduced is not clear, but it should be used sooner rather than later [31]. The study by BROCHARD et al. [2] showed that endotracheal intubation, even though associated complications which, in turn lead to a lengthening in hospital stay, is at this time the only alternative in patients who failed to improve with noninvasive mechanical ventilation; eight out of $11(73 \%)$ patients who failed NPPV survived after employing conventional mechanical ventilation and were discharged after $40 \pm 22$ days of hospital stay. The present study, although retrospective, is the first to compare NPV with CMV after intubation for the treatment of COPD patients with ARF. The results obtained in terms of mortality rate suggest that NPV is as effective as CMV and that the noninvasive ventilatory technique avoided endotracheal intubation in $81 \%$ of cases; only five patients needed intubation for the lack of effectiveness of NPV. This rate in preventing intubation is similar to that previously reported in COPD patients treated with noninvasive positive pressure ventilation $[2,3,9]$.

ICUs are very precious and expensive resources; the high costs are principally linked to nursing [32]. The treatment of acute chronically ill patients in ICUs has created and continues to create ethical and economic concerns $[33,34]$. The possibility of treating these patients in units with lower costs and a good level of assistance could represent a valid alternative to the use of traditional critical care units [35-38]. Patients with acute on chronic respiratory failure may experience a prolonged stay in the ICU, not only for the severe disease underlying ARF [25] but also for ICU-related complications [1]. The hours of mechanical ventilation were significantly fewer in patients treated with NPV than in those with CMV; this finding 
could be important because the duration of mechanical ventilation is a critical factor for the development of several complications [39]. The difference in duration of mechanical ventilation between cases and controls is remarkable; it must be considered, however, that during $\mathrm{CMV}$, frequent use of sedatives and neuromuscular blocking agents may contribute to the prolonged application of mechanical ventilation. Furthermore, as reported by ESTEBAN et al. [40], in COPD patients in ARF the weaning period accounted for $59 \%$ of the total duration of CMV. This point needs further evaluation, given that the present study was retrospective and no standardized criteria for CMV were employed. The data in this study show that three patients treated with CMV in the ICU developed pneumonia, whereas none of the patients treated with NPV in the RIICU developed any infective complications. However, there was no difference in the length of hospital stay between patients treated noninvasively in the RIICU and those treated with CMV in the ICU. The different nurse/ patient ratio in the two different settings could justify different costs in favour of an intermediate respiratory care unit.

The data reported in this study must be analysed with caution, bearing in mind some limitations. The retrospective design, the different teams involved in the management of these particular patients, which could imply different expertise, and a possible difference in the medical treatment employed could all influence the results. It must be stressed, however, in both settings that the study was carried out with the level of assistance assured by well-trained personnel with a high level of expertise and was performed during the same period, which is a guarantee of the same medical treatment used in the two settings.

In conclusion, the data of this preliminary study suggest that negative pressure ventilation is as effective as conventional mechanical ventilation in preventing death, which may occur during acute respiratory failure in patients with chronic obstructive pulmonary disease. Treatment of chronic obstructive pulmonary disease patients with acute respiratory failure in a respiratory intermediate intensive care unit seems to be as safe as an intensive care unit but less costly and this point is particularly important where economic resources are limited. A prospective, randomized cost-effectiveness study comparing the two strategies may be justified.

\section{References}

1. Pingleton SK. Complication of acute respiratory failure. Am Rev Respir Dis 1988; 137: 1463-1493.

2. Brochard L, Mancebo J, Wysocki M, et al. Noninvasive ventilation for acute exacerbations of chronic obstructive pulmonary disease. $N$ Engl J Med 1995; 333: 817-822.

3. Kramer N, Mayer TJ, Meharg J, Cece RD, Hill NS. Randomized, prospective trial of noninvasive positive pressure ventilation in acute respiratory failure. Am J Respir Crit Care Med 1995; 151: 1799-1806.

4. Confalonieri M, Parigi P, Scartabellati A, et al. Noninvasive mechanical ventilation improves the immediate and long-term outcome of COPD patients with acute respiratory failure. Eur Respir J 1996; 9: 422-430.

5. Bott J, Carroll MP, Conway JH, et al. Randomised controlled trial of nasal ventilation in acute ventilatory failure due to chronic obstructive airways disease. Lancet 1993; 341: $1555-1557$.
6. Ambrosino N, Foglio K, Rubini F, Clini E, Nava S, Vitacca M. Non-invasive mechanical ventilation in acute respiratory failure due to chronic obstructive pulmonary disease: correlates for success. Thorax 1995; 50: 755757.

7. Ambrosino N. Noninvasive mechanical ventilation in acute respiratory failure. Eur Respir J 1996; 9: 795-807.

8. Corrado A, De Paola E, Gorini M, et al. Intermittent negative pressure ventilation in the treatment of hypoxic hypercapnic coma in chronic respiratory insufficiency. Thorax 1996; 51: 1077-1082.

9. Vitacca M, Clini E, Rubini F, Nava S, Foglio K, Ambrosino N. Non-invasive mechanical ventilation in severe chronic obstructive lung disease and acute respiratory failure: short-and long-term prognosis. Intensive Care Med 1996; 22: 94-100.

10. Teasdale G. Assessment of coma and impaired consciousness: a practical scale. Lancet 1974; i: 81-83.

11. Knaus WA, Draper EA, Wagner DP, Zimmerman JE. APACHE II: a severity of disease classification system. Crit Care Med 1985; 13: 818-829.

12. Fleiss JL. Statistical Methods for Rates and Proportions. New York, Wiley \& Sons, 1981; pp. 112-137.

13. Senef MG, Wagner DP, Wagner RP, Zimmerman JE, Knaus WA. Hospital and 1-year survival of patients admitted to intensive care units with acute exacerbation of chronic obstructive pulmonary disease. JAMA 1995; 274 : 1852-1857.

14. Heuser MD, Case LD, Ettinger WH. Mortality in intensive care patients with respiratory disease. Is age important? Arch Intern Med 1992; 152: 1638-1688.

15. Feldman C, Kallenbach JM, Levy H, et al. Community-acquired pneumonia of diverse etiology: prognostic features in patients admitted to an intensive care unit on a "severity of illness" score. Intens Care Med 1989; 15: 302-307.

16. Leeper KV, Torres A. Community acquired pneumonia in the intensive care unit. Clin Chest Med 1995; 16: 155172.

17. Warren PM, Millar JS, Avery F, et al. Respiratory failure revisited: acute exacerbations of chronic bronchitis between 1961-68 and 1970-76. Lancet 1980; i: 467-470.

18. Jeffrey AA, Warren PM, Flenley DC. Acute hypercapnic respiratory failure in patients with chronic obstructive lung disease: risk factors and use of guidelines for management. Thorax 1992; 47: 34-40.

19. Corrado A, Bruscoli G, Messori A, et al. Iron lung treatment of subjects with COPD in acute respiratory failure. Chest 1992; 101: 692-696.

20. Sun X, Hakim RB, Knaus WA, Muir JF. Prognosis of acute respiratory failure in patients with chronic obstructive pulmonary disease. In: Derenne JP, Whitelaw WA, Similowski T, eds. Acute Respiratory Failure in Chronic Obstructive Pulmonary Disease. New York, Dekker 1996; pp. 559-577.

21. Knaus WA. Prognosis with mechanical ventilation: the influence of disease, severity of disease, age, and chronic health status on survival from an acute illness. Am Rev Respir Dis 1989; 140: S8-S13.

22. Medical Research Council (MRC) Working Party. Long term domiciliary oxygen therapy in chronic hypoxic cor pulmonale complicating chronic bronchitis and emphysema. Lancet 1981; i: 681-686.

23. Chailleux E, Fauroux B, Binet F, Dantzenberg B, Polu JM. Predictors of survival in patients receiving domiciliary oxygen therapy or mechanical ventilation. A 10-year analysis of ANTADIR observatory. Chest 1996; 109: 741-749. 
24. Menzies R, Gibbson W, Goldberg P. Determinants of weaning and survival among patients with COPD who require mechanical ventilation for acute respiratory failure. Chest 1989; 95: 398-405.

25. Rossi A, Ambrosino N. The need for an intermediate cardiorespiratory unit. Monaldi Arch Chest Dis 1994; 49: 463-465.

26. Weitzenblum E. Acute respiratory failure in the patients with obstructive airways disease. In: Fishman AP, ed. Pulmonary diseases and disorders. 2nd Edn. Vol. 3. New York, McGraw-Hill, 1988; pp. 2287-2298.

27. Benito S, Vallverdu I, Mancebo J. Which patients need a weaning technique? In: Marini JJ, Roussos Ch, eds. Ventilatory Failure, Update in Intensive Care and Emergency Medicine 15. Berlin, Springer, 1991; pp. 419429.

28. Kettle LH. The management of respiratory failure in chronic obstructive lung disease. Med Clin North Am 1973; 57: 781-792.

29. Sluiter HJ, Blokzyl EJ, van Dijl W, van Haeringen JR, Hilvering C, Steenhuis EJ. Conservative and respirator treatment of acute respiratory insufficiency in patients with chronic obstructive lung disease: a reappraisal. $A m$ Rev Respir Dis 1972; 105: 932-942.

30. Hudson LD. Survival data in patients with acute and chronic lung disease requiring mechanical ventilation. Am Rev Respir Dis 1989; 140: S19-S24.

31. Elliott MW. Noninvasive ventilation in chronic obstructive lung disease. $N$ Engl J Med 1995; 333: 870871.
32. Noseworthy T, Konopad E, Johnston R, Shustack A, Grace M. The cost of intensive care. Chest 1992; 102: Suppl, 150S.

33. Douglass PS, Bone RC, Rosen RL. DRG payments for long-term ventilator patients. Chest 1987; 91: 415-417.

34. Gracey DR, Gillespie D, Nobrega F, et al. Financial implication of prolonged ventilator care of Medicare patients under the prospective payment system. Chest 1987; 91: 424-477.

35. Krieger BP, Ershowsky P, Spivack D, Thorstenson J, Sackner MA. Initial experience with a central respiratory monitoring unit as a cost-saving alternative to the intensive care unit for Medicare patients who require longterm ventilator support. Chest 1988; 93: 395-397.

36. Bone RC, Balk RA. Noninvasive respiratory care unit: a cost effective solution for the future. Chest 1988; 93 : 390-394.

37. Krieger BP, Ershowsky P, Spivack D. One year's experience with a non invasively monitored intermediate unit for pulmonary patients. JAMA 1990; 264: 1143-1146.

38. Elpern EH, Silver MP, Rosen RL, Bone AC. A cost-effective approach for mechanically ventilated patients. Chest 1990; 98: Suppl.,75S.

39. Langer M, Mosconi P, Cigada M. Mandelli M, Intensive Care Unit Group of Infection Control. Long-term respiratory support and risk of pneumonia in critically ill patients. Am Rev Respir Dis 1989; 140: 302-305.

40. Esteban A, Alia I, Ibanez J, Benito S, Tobin MJ. Spanish Lung Failure Collaborative Group. Modes of mechanical ventilation and weaning. A national survey in Spanish hospitals. Chest 1994; 106: 1188-1193. 